\title{
Review
}

\section{Genes Associated with Fatty Acid Composition of Beef}

\author{
Hideyuki MANNEN $^{*}$ \\ Laboratory of Animal Breeding and Genetics, Graduate School of Agricultural Science, Kobe University, 1-1 Rokkoudai, Nada, Kobe \\ 657-8501, Japan
}

Received July 5, 2011; Accepted August 8, 2011

Fatty acid composition has become recognized as an important trait in beef because of its relationship with beef quality, including beef flavor and tenderness. Our laboratory attempted to identify genes responsible for the fatty acid composition of cattle. We found several such genes and developed genetic markers of fatty acid composition. The findings were as follows. 1) Genetic polymorphisms of the stearoylCoA desaturase $(S C D)$ gene are associated with fatty acid composition. The effects of $S C D$ type A gene substitution on the percentage of monounsaturated fatty acid (MUFA) and the melting point of intramuscular fat were on average approximately $+1.0 \%$ and $-1.0^{\circ} \mathrm{C}$, respectively. 2) Intron polymorphisms of sterol regulatory element binding protein-1 (SREBP-1) also affected MUFA. 3) No effect of SCD or SREBP-1 genotypes on any representative carcass traits of Japanese Black cattle was observed in the field population. 4) Additional genetic markers, adipocytes fatty acid binding protein 4 (FABP4) and liver X receptor $\alpha$, also affected the fatty acid composition. 5) $S C D$ and $F A B P 4$ significantly affected fatty acid composition of Holstein steers. These findings bring new insights into the fat-related carcass traits of beef cattle. In addition, the developed DNA makers will contribute to improved meat quality of beef.

Keywords: adipose tissue, beef quality, fatty acid composition, stearoyl-CoA desaturase, sterol regulatory element binding protein

\section{Introduction}

Beef of Japanese Black cattle in Japan is valued for its highly marbled meat. Moreover, the melting point of its fat is relatively low compared to that of other breeds. The lower melting point is caused by the higher percentage of unsaturated fatty acids in the fat (Yang et al., 1999a). Recently, the fatty acid composition of adipose tissue in beef cattle has become recognized as an important trait in the beef industry. In cattle, higher concentrations of monounsaturated fatty acids (MUFA) in the adipocytes and a lower fat-melting point are considered to contribute to the softness of beef fat, favorable beef flavor, and may decrease the circulating concentration of LDL cholesterol (Melton et al., 1982; Rudel et al., 1995; Smith et al., 1994).

The fatty acid composition of cattle, unlike that in nonruminants, is much less dependent on diet. Microorganisms within the rumen hydrogenate a majority of the dietary

*To whom correspondence should be addressed.

E-mail: mannen@kobe-u.ac.jp unsaturated fatty acids and most dietary fatty acids are absorbed as saturated fatty acids (Jenkins, 1993). However, it is reported that diet also influences bovine fatty acid composition (Edwards et al., 1961; Cabezas et al., 1965). Zembayashi et al. (1995) demonstrated that adipose tissue of Japanese Black cattle contains a higher proportion of MUFA than that of Holstein, Japanese Brown or Charolais cattle. Oka et al. (2002) demonstrated that sire groups had a significant effect on the fatty acid composition of Japanese Black cattle. In addition to various environmental effects (HuertaLeidenz et al., 1991; Chang et al., 1992; Suzuki et al., 2007), these results suggest that fatty acid composition could be controlled by genetic factors such as lipid synthesis and fatty acid metabolism-related genes.

Recently, genes responsible for the fatty acid composition of beef have been identified, and the number of reports on this topic is increasing. Here, I would like to review the current research on genes responsible for the fatty acid composition of cattle. 


\section{Stearoyl-CoA desaturase}

Stearoyl-CoA desaturase (SCD) is an enzyme responsible for the conversion of saturated fatty acids into MUFA in mammalian adipocytes. The fatty acid composition reflects the preceding actions of SCD on substrates such as stearic acid or palmitic acid (Kim and Ntambi, 1999). Nutrition has been shown to contribute to the fatty acid profile, while genetic factors are still being elucidated. SCD is a candidate for genetic variation in fatty acid composition. Yang et al. (1999b) presented interesting correlations between SCD enzyme activity and fatty acid composition in a survey of bovine adipose tissues.

We sequenced full-length bovine $S C D$ cDNA and the 5 '-upstream region (Taniguchi et al., 2004a). The full length of the $S C D$ cDNA was 5,331 bp and the protein-coding sequence (CDS) contained 1,080 nucleotides coding for 359 amino acids. A comparison of the SCD sequence between 20 Japanese Black animals showed eight nucleotide substitutions: three substitutions were in CDS and five were in the 3' UTR (Fig. 1). Nucleotide substitution at 878 bp in CDS causes replacement of the amino acid valine ( $\mathrm{V}$ type) with alanine (A type) in the SCD peptide.

\section{$S C D$ polymorphism and fatty acid composition}

Genotyping of 1,003 Japanese Black steers for the nonsynonymous polymorphism was carried out to investigate the relationship between $S C D$ genotypes and fatty acid composition or fat-melting point of fattened Japanese Black steers (Taniguchi et al., 2004a). The means of the proportion of MUFA and the melting point of intramuscular fat for three $S C D$ genotypes are shown in Table 1 . The differences were significant in the percentage of MUFA (high in type AA, medium in type $\mathrm{AV}$, low in type $\mathrm{VV}$ ). The melting point of intramuscular fat tissue was also significantly different between $S C D$ genotypes (high in type $\mathrm{VV}$, medium in type $\mathrm{AV}$, low in type AA). The effect of $S C D$ type A gene substitution on the percentage of MUFA and the melting point of intramuscular fat was $+0.805 \%$ and $-1.03^{\circ} \mathrm{C}$, respectively (Taniguchi et al., $2004 \mathrm{a})$. The genotype accounted for $4 \%$ of the total variation in MUFA and 3\% of that in the melting point of intramuscular fat.

\section{Sterol regulatory element binding protein-1}

As described above, polymorphism of the $S C D$ gene is associated with fatty acid composition. Since $S C D$ gene expression is possibly related to this trait, the effect of gene expression was investigated. The results showed that the level of SCD mRNA expression in Japanese Black cattle (132.1 \pm 34.1) was significantly higher $(P<0.05)$ than that in Holstein cattle (39.5 \pm 12.9$)$ (Taniguchi et al., 2004b). Japanese Black cattle had a consistently higher $(P<0.05)$ percentage of mono-unsaturated fatty acids than did Holstein cattle. These results suggest that differences in $S C D$ gene expression may contribute to the fatty acid compositional differences seen between Japanese Black and Holstein cattle.

The above studies revealed that $S C D$ mRNA expression level is related to the MUFA percentage differences between cattle breeds. Sterol regulatory element binding proteins (SREBPs) are transcription factors that play a central role in energy homeostasis by promoting glycolysis, lipogenesis, and adipogenesis. SREBPs belong to the original basic helixloop-helix-leucine zipper family of transcription factor (Eb-

Table 1. Comparison of MUFA content and melting point of fat tissue between two $S C D$ genotypes.

\begin{tabular}{crcc}
\hline Genotype & $\mathrm{n}$ & MUFA $(\%)$ & Melting point $\left({ }^{\circ} \mathrm{C}\right)$ \\
\hline AA & 278 & $58.8 \pm 0.1^{\mathrm{a}}$ & $25.4 \pm 0.2^{\mathrm{a}}$ \\
AV & 635 & $58.2 \pm 0.1^{\mathrm{b}}$ & $26.1 \pm 0.1^{\mathrm{b}}$ \\
VV & 90 & $57.1 \pm 0.3^{\mathrm{c}}$ & $27.6 \pm 0.3^{\mathrm{c}}$ \\
\hline
\end{tabular}

Adipose from M. trapezius was used in this study. Modified from Taniguchi et al. (2004a).

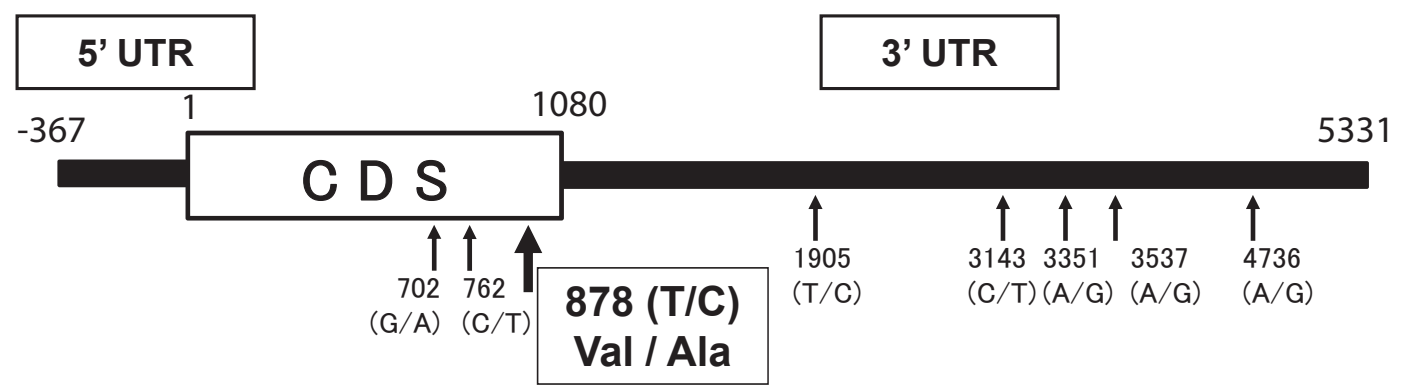

Fig. 1. Full-length bovine stearoyl-CoA desaturase cDNA. The full-length bovine SCD is 5,331 bp long. The proteincoding sequence (CDS) contains 1,080 nucleotides coding for 359 amino acids, and the 3' un-translated region (UTR) contains 3,884 nucleotides. Arrows show the positions of eight nucleotide substitutions, and the box indicates nucleotide mutation sites resulting in amino acid replacement. 
erle et al., 2004). In humans and mice, the SREBP-1 gene produces two proteins by alternative splicing: SREBP-1a and 1c (Eberle et al., 2004). It is known that SREBPs regulate gene transcription activation by binding to sterol regulatory element sequences contained in the promoter of their downstream genes, including the $S C D$ gene (Shimano, 2001).

Subsequently, we determined the full-length sequence of bovine SREBP-1 cDNA and then surveyed polymorphisms in whole exons and introns in the bovine genome (Hoashi et al., 2007). Although there were no notable mutations (e.g., nonsynonymous polymorphisms) in exon regions, a large 84-bp insertion (long type: L) and a deletion (short type: S) were found in intron 5 of bovine SREBP-1 in Japanese Black cattle. The associations between the SREBP-1 genotypes and fatty acid composition were analyzed in 606 Japanese Black cattle. The SS type of cattle exhibited a $1.3 \%$ higher proportion of MUFA and a $1.6^{\circ} \mathrm{C}$ lower melting point in intramuscular fat than the LL type of cattle (Table 2). Bovine $S R E B P$-1 genotype is considered to reflect a genetic variation associated with the physiological characteristics of fat tissue in Japanese Black cattle.

\section{No effect of SCD or SREBP-1 genotypes on any represen- tative carcass traits of Japanese Black cattle in the field population}

Our studies showed that the SCD and SREBP polymorphisms affect fatty acid composition of bovine adipose tissue. However, the effects on field populations had not been confirmed, and the effects of these DNA markers on carcass traits had not been evaluated. Therefore, we investigated the effects of SCD and SREBP-1 on beef carcass traits (carcass weight, rib eye area, rib thickness, subcutaneous fat thickness, yield estimate, beef marbling score, beef color standard) using field cattle populations (Ohsaki et al., 2009).

The results showed no effect of $S C D$ and $S R E B P-1$ genotypes on any representative carcass traits of Japanese Black cattle in the field population. This implies that there are no adverse effects on other representative carcass traits when marker-assisted selection is performed using these genetic markers in Japanese Black cattle.

\section{Other genes associated with fatty acid composition}

Fatty acid synthase (FASN) is a multifunctional enzyme that regulates de novo biosynthesis of long chain fatty acids in mammals (Smith, 1994). Abe et al. (2009) revealed that the FASN genotype had a significant effect on the fatty acid composition of an $\mathrm{F}_{2}$ population from Japanese Black and Limousin cattle. Two mutations led to amino acid substitutions of threonine (T) with alanine (A) and of tryptophan (W) with arginine (R). The TW haplotype was associated with
Table 2. Comparison of MUFA content and melting point of intramuscular fat among SREBP genotypes.

\begin{tabular}{crcc}
\hline Genotype & \multicolumn{1}{c}{$\mathrm{n}$} & MUFA $(\%)$ & Melting point $\left({ }^{\circ} \mathrm{C}\right)$ \\
\hline LL & 98 & $57.7 \pm 0.3^{\mathrm{a}}$ & $26.7 \pm 0.4^{\mathrm{a}}$ \\
LS & 437 & $58.1 \pm 0.2^{\mathrm{a}}$ & $26.3 \pm 0.2^{\mathrm{a}}$ \\
SS & 71 & $59.0 \pm 0.3^{\mathrm{b}}$ & $25.1 \pm 0.4^{\mathrm{b}}$ \\
\hline
\end{tabular}

Mean values with different superscripts in the same column differ significantly $(P<0.05)$.

Modified from Hoashi et al. (2007).

increased C18:0 and C18:1 content and in the ratio of monounsaturated to saturated fatty acids, along with decreased C14:0, C14:1, C16:0, and C16:1 content.

We also surveyed additional genetic markers associated with fatty acid composition (Hoashi et al. 2008). The fulllength CDS for six genes, adipocytes fatty acid binding protein (FABP4), liver X receptor a (LXR $)$, cytochrome $b_{5}$, long-chain acyl-CoA synthetase (ACSL) 1, ACSL4, and diacylglycerol acyltransferase 2, were sequenced to identify polymorphisms in Japanese Black and Holstein cattle. For $F A B P 4$, two nucleotide substitutions were predicted to cause amino acid substitutions, from isoleucine to valine at 220 bp A/G (I74V) and from valine to methionine at $328 \mathrm{bp} \mathrm{G} /$ A (V110M). For $L X R \alpha$, two nucleotide substitutions were predicted to cause amino acid substitutions, from glycine to glutamic acid at $152 \mathrm{bp} \mathrm{G/A}(\mathrm{G} 51 \mathrm{E})$ and from valine to isoleucine at $397 \mathrm{bp} \mathrm{G/A}(\mathrm{V} 133 \mathrm{I})$.

The FABP4 is a member of the cytoplasmic protein family involved in intracellular free fatty acid transport and metabolism, and binds long-chain fatty acids with high affinities. Fatty acid trafficking during lipolysis is mediated by FABP4, and the complex with hormone-sensitive lipase is the first step in an organized lipid-transfer process (Shen et $a l ., 1999)$. LXR $\alpha$ is a transcription factor that regulates genes involved in cholesterol and lipid metabolism. LXR directly activates SREBP-1 gene transcription, and the SREBP-1 subsequently activates lipogenic genes such as $F A S N$ and $S C D-1$ (Schultz et al., 2000; DeBose-zboyd et al., 2001).

The effects of four nonsynonymous substitutions in $F A B P 4$ and $L X R \alpha$ were investigated using a Japanese Black cattle population (Hoashi et al., 2008). The FABP4 I74V had a highly significant effect on the percentage of C16:1. $\mathrm{LXR} \alpha \mathrm{V} 133 \mathrm{I}$ had a significant effect on the percentage of C18:2, while no significant effect was found with the polymorphisms FABP4 V110M and LXR $\alpha$ G51E. Table 3 presents the means of the significant differences in fatty acid and index proportion among genotypes.In FABP4 I74V, I/I homozygotes exhibited a significantly higher percentage of C16:1 than V/V homozygotes, reflecting a high proportion 
Table 3. Effect of FABP4 I74V and LXR $\alpha$ V133I on fatty acid composition of Japanese Black cattle.

\begin{tabular}{|c|c|c|c|c|c|c|}
\hline & \multicolumn{3}{|c|}{ I74V of $F A B P 4$} & \multicolumn{3}{|c|}{ V133I of $L X R \alpha$} \\
\hline & $\begin{array}{c}\mathrm{I} / \mathrm{I} \\
\mathrm{n}=82\end{array}$ & $\begin{array}{c}\mathrm{I} / \mathrm{V} \\
\mathrm{n}=113\end{array}$ & $\begin{array}{c}\mathrm{V} / \mathrm{V} \\
\mathrm{n}=39\end{array}$ & $\begin{array}{c}\mathrm{V} / \mathrm{V} \\
\mathrm{n}=174\end{array}$ & $\begin{array}{c}\mathrm{V} / \mathrm{I} \\
\mathrm{n}=54\end{array}$ & $\begin{array}{c}\mathrm{I} / \mathrm{I} \\
\mathrm{n}=6\end{array}$ \\
\hline \multicolumn{7}{|l|}{ Fatty acid composition $(\%)$} \\
\hline $\mathrm{C} 16: 1$ & $3.76^{\mathrm{a}}$ & $3.56^{\mathrm{ab}}$ & $3.25^{\mathrm{b}}$ & 3.65 & 3.67 & 3.25 \\
\hline C18:2 & 1.95 & 2.1 & 2.14 & $2.08^{b}$ & $2.30^{\mathrm{a}}$ & $1.79^{\mathrm{ab}}$ \\
\hline MUFA & 56.45 & 56.73 & 56.21 & 56.2 & 56.83 & 56.36 \\
\hline $\mathrm{C} 16: 1 /(\mathrm{C} 16: 0+\mathrm{C} 16: 1)$ & $12.23^{\mathrm{a}}$ & $11.88^{\mathrm{ab}}$ & $10.95^{\mathrm{b}}$ & 11.94 & 12.25 & 10.87 \\
\hline
\end{tabular}

Mean values with different superscripts in the same column differ significantly $(P<0.05)$.

Modified from Hoashi et al. (2008).

of C16:1 / C16:0 + C16:1. V/I heterozygotes in LXR $\alpha$ V133I exhibited a significantly higher percentage of C18:2 than $\mathrm{V} /$ V homozygotes.

Additional analyses using different field populations are needed in the near future to confirm the effects of these three genes.

\section{The gene effect in other breeds}

While Holstein is most famous for milk production, they are also an important source of domestic beef in Japan. Therefore, we investigated the effects of genetic polymorphisms in SCD, SREBP-1, FASN, LXR $\alpha$ and FABP4 on the fatty acid composition of Holstein steers (Narukami et al., in press).

The major allele frequencies were 0.705 in $S C D, 1.000$ in SREBP-1, 0.518 in FABP4, 0.888 in FASN, and 0.984 in $L X R \alpha$. The SCD V293A had significant effects on the percentages of C14:0, C14:1, C18:0, C18:1, MUFA and SFA. The FABP4 I74V had a significant effect on the percentage of C16:0, while no significant effect was observed with FASN T1952A. Analysis of the effects on $L X R a$ and SREBP-1 genotypes were not possible due to the extremely biased genotype frequencies.

Zhang et al. (2008) reported that amino acid substitution in the TE domain of the FASN gene was associated with beef fatty acid composition of Angus bulls. Michal et al. (2006) demonstrated that the FABP4 genotype significantly affects the marbling score using $\mathrm{F}_{2}$ animals in a Wagyu $\times$ Limousin cross.

\section{Conclusions}

Recently, fatty acid composition has become recognized as an important beef trait. In this review paper, I summarized recent studies on the identification of genes associated with the fatty acid composition of cattle. Economic traits, such as the fatty acid composition, have been considered as a polygenic trait. Quantitative trait locus analysis has indicated that the fatty acid composition of livestock species is regulated by many potential candidate genes with small effects (Taylor et al., 1998; Sanchez et al., 2007; Abe et al., 2008). Additionally, differential expression of adipogenic factors is known to play a key role in regulating multiple responsive pathways involved in fat development and lipid metabolism in cattle adipocytes (Taniguchi et al., 2008). Although the adipogenic mechanism is extremely complicated, some genes have been elucidated and confirmed to be associated with the fatty acid composition of cattle. Further analysis will bring new insights into fat-related carcass traits of beef cattle, while contributing to the beef industry and to human food health throughout the world.

Acknowledgement I thank Dr. Soichi Tsuji, Dr. Fumio Mukai, Dr. Shinji Sasazaki, Dr. Masaaki Taniguchi, Dr. Kenji Oyama, Dr. Takeshi Honda, and all of the students in our laboratory for their experimental ideas, sincere help, and critical discussions. I also thank the Wagyu Registry Association, the Livestock Improvement Association of Japan Inc., research institutes of several prefectures, the National Livestock Breeding Center, the Japan Livestock Technology Association and the Society for Researches on Native Livestock Japan for providing cattle samples and data.

\section{References}

Abe, T., Saburi, J., Hasebe, H., Nakagawa, T., Kawamura, T., Saito, K., Nade, T., Misumi, S., Okumura, T., Kuchida, K., Hayashi, T., Nakane, S., Mitsuhasi, T., Nirasawa, K., Sugimoto, Y. and Kobayashi, E. (2008). Bovine QTL analysis for growth, carcass, and meat quality traits in an F2 population from a cross between Japanese Black and Limousin. J. Anim. Sci., 86, 2821-2832.

Abe, T., Saburi, J., Hasebe, H., Nakagawa, T., Misumi, S., Nade, T., Nakajima, H., Shoji, N., Kobayashi, M. and Kobayashi, E. (2009). 
Novel mutations of the FASN gene and their effect on fatty acid composition in Japanese Black beef. Biochem. Genet., 47, $397-$ 411.

Cabezas, M., Hentges, J., Moore, J. and Olson, J. (1965). Effect of diet on fatty acid composition of body fat in steers. J. Anim. Sci., 24, 57-61.

Chang, J.H., Lunt, D.K. and Smith, S.B. (1992). Fatty acid composition and fatty acid elongase and stearoyl-CoA desaturase activities in tissues of steers fed high oleate sunflower seed. J. Nutr., 122, 2074-2080.

DeBose-Boyd, R.A., Ou, J., Goldstein, J.L. and Brown, M.S. (2001). Expression of sterol regulatory element-binding protein 1c (SREBP-1c) mRNA in rat hepatoma cells requires endogenous LXR ligands. Proc. Natl. Acad. Sci. U.S.A., 98, 1477-1482.

Eberle, D., Hegarty, B., Bossard, P., Ferre, P. and Foufelle F. (2004). SREBP transcription factors, master regulators of lipid homeostasis. Biochimie, 86, 839-848.

Edwards, R., Tove, S., Blumer, T. and Barrick, E. (1961). Effects of added dietary fat on fatty acid composition and carcass characteristics of fatting steers. J. Anim. Sci., 20, 712-717.

Hoashi, S., Ashida, N., Ohsaki, H., Utsugi, T., Sasazaki, S., Taniguchi, T., Oyama, K., Mukai, F. and Mannen, H. (2007). Genotype of bovine Sterol Regulatory Element Binding Protein-1 (SREBP-1) is associated with fatty acid composition in Japanese Black cattle. Mamm. Genome, 18, 880-886.

Hoashi, S., Hinenoya, T., Tanaka, A., Ohsaki, H., Sasazaki, S., Taniguchi, M., Oyama, K., Mukai, F. and Mannen, H. (2008). Association between fatty acid compositions and genotypes of FABP4 and LXR $\alpha$ in Japanese Black cattle. BMC Genet., 9, 84.

Horton, J.D., Shimomura, I., Brown, M.S., Hammer, R.E., Goldstein, J.L. and Shimano, H. (1998). Activation of cholesterol synthesis in preference to fatty acid synthesis in liver and adipose tissue of transgenic mice overproducing sterol regulatory elementbinding protein-2. J. Clin. Invest., 101, 2331-2339.

Huerta-Leidenz, N.O., Cross, H.R., Lunt, D.K., Pelton, L.S., Savell, J.W. and Smith, S.B. (1991). Growth, carcass traits, and fatty acid profiles of adipose tissues from steers fed whole cottonseed. $J$. Anim. Sci., 69, 3665-3672.

Jenkins, C. (1993). Lipid metabolism in the rumen. J. Daily Sci., 76, 3851-3863.

Kim, Y.C. and Ntambi, J.M. (1999). Regulation of stearoyl-CoA desaturase genes: role in cellular metabolism and preadipocyte differentiation. Biochem. Biophys. Res. Commun., 266, 1-4.

Melton, L., Amiri, M., Davis, W. and Backus, R. (1982). Flavor and chemical characteristics of ground beef from grass-, forage-grainand grain-finished steers. J. Anim. Sci., 55, 77-87.

Narukami, T., Sasazaki, S., Oyama, K., Nogi, T., Taniguchi, M. and Mannen, H. Effect of DNA polymorphisms related to fatty acid composition in adipose tissue of Holstein cattle. Anim. Sci. J., In press.
Ohsaki, H., Tanaka, A., Hoashi, S., Sasazaki, S., Oyama, K.,Taniguchi, M., Mukai, F. and Mannen, H. (2009). Effect of SCD and SREBP genotypes on fatty acid composition in adipose tissue of Japanese Black cattle herds. Anim. Sci. J., 80, 225-232.

Oka, A., Iwaki, F., Dohgo, T., Ohtagaki, S., Noda, M., Shiozaki, T., Endoh, O. and Ozaki, M. (2002). Genetic effects on fatty acid composition of carcass fat of Japanese Black Wagyu steers. $J$. Anim. Sci., 80, 1005-1011.

Rudel, L., Park, S. and Sawyer, K. (1995). Compared with dietary monounsaturated and saturated fat, polyunsaturated fat protects African green monkeys from coronary artery athero-sclerosis. Arterioscler. Thromb. Vasc. Biol., 15, 2101-2110.

Sanchez, P., Iannuccelli, N., Basso, B., Bidanel, P., Billon, Y., Gandemer, G., Gilbert, H., Larzul, C., Legault, C., Riquet, J., Milan, D. and Le Roy, P. (2007). Identification of QTL with effects on intramuscular fat content and fatty acid composition in a Duroc $\times$ Large White cross. BMC Genet., 8, 55.

Schultz, R., Tu, H., Luk, A., Repa, J., Medina, C., Li, L., Schwendner, S., Wang, S., Thoolen, M., Mangelsdorf, J., Lustig, D. and Shan, B. (2000). Role of LXRs in control of lipogenesis. Genes Dev., 14, 2831-2838.

Shen, W.J., Bernlohr, K., Sridhar, D.A. and Kraemer, F.B. (1999). Interaction of rat hormone-sensitive lipase with adipocyte lipidbinding protein. Proc. Natl. Acad. Sci. U.S.A., 96, 5528-5532.

Shimano, H. (2001). Sterol regulatory element-binding proteins (SREBPs), transcriptional regulators of lipid synthetic genes. Prog. Lipid Res., 40, 439-452.

Smith, S. (1994). The animal fatty acid synthase: one gene, one polypeptide, seven enzymes. FASEB J., 8, 1248-1259.

Suzuki, S., Ishikawa, S., Arihara, K. and Itoh, M. (2007). Changes in molecular species composition of triacylglycerol in subcutaneous fat from beef cattle during fattening. Anim. Sci. J., 78, 293300 .

Taylor, J., Coutinho, L., Herring, K., Gallagher, D., Brenneman, R., Burney, N., Sanders, J., Turner, J., Smith, S., Miller, R., Savell, J. and Davis, S. (1998). Candidate gene analysis of GH1 for effects on growth and carcass composition of cattle. Animal Genetics, 29, 194-201.

Taniguchi, M., Guan, L.L., Zhang, B., Dodson, M.V., Okine, E. and Moore, S.S. (2008). Gene expression patterns of bovine perimuscular preadipocytes during adipogenesis. Biochem. Biophys. Res. Commun., 366, 346-351.

Taniguchi, M., Mannen, H., Oyama, K., Shimakura, Y., Oka, A., Watanabe, H., Kojima, T., Komatsu, M., Harper, G.S. and Tsuji, S. (2004b). Differences in stearoyl-CoA desaturase mRNA levels between Japanese Black and Holstein cattle. Livestock Prod. Sci., 87, 215-220.

Taniguchi, M., Utsugi, T., Oyama, K., Mannen, H., Kobayashi, M., Tanabe, Y., Ogino, A. and Tsuji, S. (2004a). Genotype of stearoylCoA desaturase is associated with fatty acid composition in Japa- 
nese Black cattle. Mamm. Genome, 15, 142-148.

Yang, A., Larsen, W., Powell, H. and Tume, K. (1999a). A comparison of fat composition of Japanese and long-term grain-fed Australian steers. Meat Sci., 51, 1-9.

Yang, A., Larsen, T.W., Smith, S.B. and Tume, R.K. (1999b). $\Delta 9$ desaturase activity in bovine subcutaneous fatty acid composi- tion. Lipids, 34, 971-978.

Zembayashi, M., Nishimura, K., Lunt, K. and Smith, B. (1995). Effect of breed type and sex on the fatty acid composition of subcutaneous and intramuscular lipids of finishing steers and heifers. $J$. Anim. Sci., 73, 3325-3332. 